


RECIBIDO: $31 / 10 / 2019$

ACEPTADO: $10 / 04 / 2020$

\section{RESUMEN}

Walt Disney es una de las productoras norteamericanas de cine de animación que perdura en el tiempo.

De esta manera se transmite un mensaje sexista, misógino y machista a lo largo de las figuras que dan vida a sus historias, especialmente con quienes desarrollan el rol de princesas. Por ello se precisa una revisión crítica de la colección "clásicos Disney" que manifieste las características físicas que esta compañía de cine destina hacia sus personajes femeninos y que contribuye a la transmisión y asimilación de un discurso que estereotipa a la mujer y al comportamiento del hombre hacia ella. Una vez analizados los mensajes que se mantienen en la sociedad y que impiden el progreso de la humanidad hacia un plano mucho más igualitario, en materia de derechos universales, se recurre a alternativas artísticas para establecer un contra-discurso que sea utilizado en educación y que apoye la inclusión de la diversidad. Un ejemplo clave se encuentra en el trabajo de Alexsandro Palombo quien rediseña a la princesas Disney atribuyéndoles diferentes diversidades funcionales. Se necesitan dibujos animados como los citados para que la diversidad se reconozca en estos productos audiovisuales y se normativice. Liberando así a las mujeres de la opresión social.

\section{PALABRAS CLAVE}

\section{ABSTRACT}

Walt Disney, that is one of the North-American animation film companies, is going on time. As a consequence, a sexist, misogynist and macho message is transmitted with its characters; especially with the princesses. For this reason, it is needed a critical revision of Classics set of Walt Disney, to share the physical aspects that royalty girls have in this cinema company and to share the stereotypes that are preserved during the passage of years. After this critical revision, it is introduced the art-work of Alexsandro Palombo who creates new princesses with functional diversity. In fact, more cartoons of this characteristics are required in the modern education, to be able to standardize them and to free women from social oppression. A general conclusion is that even the difficult circumstances they live in; this development helps them to survive and to face life to their common reality.

\section{KEYWORDS}




\title{
"PRINCESITAS" CON DIVERSIDAD FUNCIONAL. UNA APROXIMACIÓN CRÍTICA A LA OPRESIÓN DE REALEZA FEMENINA EN LA COLECCIÓN CINEMATOGRÁFICA "LOS CLÁSICOS” WALT DISNEY (1937-2016) Y EL CONTRA-DISCURSO CREADO POR LA OBRA ARTÍSTICA DE ALEXSANDRO PALOMBO
}

\section{Vicente Monleón}

\author{
Facultat de Magisteri, Universitat de València
}

\section{MARCO TEÓRICO}

\section{Cultura visual. Una aproximación} desde la productora Walt Disney

Las producciones Walt Disney no deben considerase productos inocuos. Por ello, la mirada al estudiar la colección de los productos cinematográficos Disney es desde la perspectiva de la cultura visual (Asebey, 2011), como campo de estudio que ayuda a comprender la forma en que se construyen identidades a partir del imaginario cotidiano. Esta ofrece a la Educación Artística una oportunidad de aprender contenidos a partir de los intereses del colectivo infantil, conectando con los gustos y preferencias del grupo de menores con conceptos de mayor complejidad. Se propone un uso de las artes como medio a través del cual es posible generar pensamiento. Esta forma de trabajo cognitivo es posible realizarlo con el grupo de discentes gracias a los recursos de la cultura visual, relacionándola con la construcción de identidades (Granado, 2003; Monleón, 2018a).

De hecho, Walt Disney es una de las productoras cinematográficas que más contribuye con su propia cultura visual a la creación de unas identidades en el colectivo infantil diferenciando desde sus inicios el sexo del hombre del de la mujer como para debilitarlas con respecto a ellos. Especialmente, esta compañía se caracteriza por la transmisión de una ideología y mentalidad sexista, misógina y machista (Monleón, 2018b). De manera subversiva se obliga a las niñas a cumplir con una serie de características para ser incluidas en la normatividad americana de la sociedad occidental, de lo contrario se las condena a quedar relegadas a la exclusión social.
Por ello, se la etiqueta como la responsable del mantenimiento de estereotipos sexistas y diferenciadora de roles de género para el hombre y la mujer. Además, no contempla posibles diversidades de índole variada para incluir a colectivos sociales en minoría y sin visibilidad en la normatividad creada por el poder. Se está hablando de la negación hacia la diversidad sexual, funcional, interculturalidad, variedad de dogmas religiosos, etc. Como consecuencia, no se contempla una alteridad real, sino que se le niega la existencia (Giovanni, 2007). Un grupo que sobrevive bajo coacción y opresión por ser considerado una alteridad pormenorizada.

Además se advierte la necesidad de abordar estos largometrajes desde una visión crítica (Pallarès, 2014) en un contexto contemporáneo que contribuya a una educación encaminada hacia las libertades, las igualdades que parten de la diferencia, la visibilidad de quienes están opacados y apartados (Ali, 2006; Freire, 2007; Gergen, 1997); buscando así un cambio y progreso social.

$Y$, para conseguir dicha transformación en la sociedad y avance en términos de justicia, se necesita recurrir a contra-discursos como el de Palombo (2014), quien a través de su trabajo ¿̇Te gustamos todavía? rediseña a las princesas Disney atribuyéndoles diversidades funcionales. Manifiesta la necesidad de estas figuras en la cultura visual cinematográfica de animación, que tiende a ocultar a las personas funcionalmente diversas a través de una "normalidad" idílicamente construida y poco representativa de la sociedad actual. Como propone artísticamente es preciso reflexionar 
sobre la necesidad de que cualquier individuo tenga representación y visibilidad en las construcciones culturales fílmicas.

Se cuenta con otros artistas contemporáneos que toman como referente a Walt Disney para repensar sus historias y combatir los discursos que construye. Algunos ejemplos son: Czarnecki (2012) que ofrece desenlaces alternativos para las historias de las princesas, Vilela (1977) en su serie fotográfica Bibidi Bobidi Boo!, Nilsson (2013) utiliza la pintura mural y la técnica del grafiti en los muros de la ciudad para conectar con los colectivos que transitan desde el arte público, el trabajo de Boy (2013) Dirtylandya en el que aparece el desnudo femenino o Happy Never After de Hoax (2014) para denunciar la violencia de género. No obstante, para esta investigación se opta por Palombo (2014) ya que es quien se centra en la problemática de la ausencia de diversidad funcional en los largometrajes de la productora de animación norteamericana.

De hecho, se espera que a partir de cambios en educación como el propuesto se consiga una transformación social que genere comunidades de personas comprometidas con el progreso real y que contribuya a la eliminación de conductas carentes de ética como las ya citadas - machismo, homofobia, sexismo, misoginia, etc. -. Todo ello partiendo de un posicionamiento educativo de corte neoliberal (Bayhan y Caner, 2017; Carr, 2015).

\section{OBJETIVOS}

\section{Objetivo principal}

El objetivo principal de esta investigación consiste en analizar a las mujeres de la realeza que aparecen en los largometrajes de la colección "Los clásicos" de Walt Disney desde un posicionamiento crítico. Estableciendo qué tipo de mensajes sexistas, machistas, homofóbicos, clasistas y racistas se transmiten y calan en el subconsciente de la audiencia que consume los productos audiovisuales, especialmente en el grupo de niñas que toman como modelos de referencia a estas princesas Disney.

\section{Objetivos secundarios}

Para cumplir con el objetivo principal es necesario desglosarlo en objetivos secundarios; más pequeños, breves y sencillos de conseguir; que tienen como principal fin cumplimentar con el primero:

- Establecer las características físicas que Walt Disney diseña para sus personajes/ mujeres de la realeza, contribuyendo a unos estereotipos sexistas y machistas en la sociedad.

- Valorar cuáles son los mensajes homofóbicos, clasistas y racistas en las figuras de dicha colección que mantienen la sublevación de la mujer al hombre y de la ocultación de colectivos sociales no normativos y considerados inferiores al grupo occidental.

- Generar un contra-discurso para ser utilizado en las aulas y contribuir de esta manera a una educación que apueste por la diversidad, especialmente de aquellos colectivos que tienden a quedar sin visibilidad como el referido a las personas funcionalmente diversas.

\section{METODOLOGÍA Y MÉTODO Metodología cualitativa - investigación basada en imágenes \\ (IBI)}

Este estudio educativo se centra en una Investigación Basada en Imágenes (Alonso-Sanz, 2013; Eisner y Barone, 2006; Marín, 2005) que es una de las maneras de proceder de la investigación cualitativa (Porta y Silva, 2003; Ramos, 2015; Pereira, 2011). Realmente el objeto de estudio en este caso concreto son los largometrajes de animación infantil de la colección "Los clásicos" de Walt Disney, una colección de 60 películas contextualizadas entre 1937 y 2016 . No obstante, más bien se recurre a la recreación de las situaciones transformadas en imágenes para estudiarlas junto a los diálogos e intervenciones que se comparten en las historias de animación. Es necesario destacar que se recurre a la cuantificación propia de la metodología cuantitativa (Conde, 1990; Ramírez y Zwerg-Villegas, 2012) para mostrar los hallazgos en cuanto a manifestación de variables de estudio. 


\section{Muestra de estudio}

Se parte de un conjunto de 60 películas de animación que componen la colección "Los clásicos" de Walt Disney (1937-2016). No obstante, simplemente se analizan 9, que son aquellas en las que aparecen mujeres como protagonistas que pertenecen a la realeza 0 bien por herencia directa o bien por contraer matrimonio con un príncipe. A continuación se comparte una tabla que muestra el listado de películas revisadas críticamente (9) y las princesas (10) que aparecen en cada una de estas.

\section{Tabla 1}

Relación princesas Disney con los clásicos donde aparecen.

\begin{tabular}{lr} 
Películas & Princesas \\
\hline $\begin{array}{l}\text { Clásico 1. Blancanieves y los siete } \\
\text { enanitos (Disney, 1937) }\end{array}$ & Blancanieves \\
\hline $\begin{array}{l}\text { Clásico 12. La Cenicienta (Disney, } \\
\text { 1950) }\end{array}$ & Cenicienta \\
\hline $\begin{array}{l}\text { Clásico 16. La bella durmiente (Dis- } \\
\text { ney, 1959) }\end{array}$ & Aurora \\
\hline $\begin{array}{l}\text { Clásico 28. La sirenita (Ashman y } \\
\text { Musker, 1989) }\end{array}$ & Ariel \\
\hline $\begin{array}{l}\text { Clásico 30. La bella y la bestia } \\
\text { (Hahn, 1991) }\end{array}$ & Bella \\
\hline
\end{tabular}

Clásico 31. Aladdin (Clements y Jasmine Musker, 1992)

Clásico 51. Tiana y el sapo (del VeTiana cho y Lasseter, 2009)

\begin{tabular}{lr}
\hline Clásico 52. Enredados (Conli, 2010) & Rapunzel \\
\hline Clásico 55. Frozen: el reino de hielo & Elsa / Anna
\end{tabular}

(del Vecho y Lasseter, 2013)

\section{Fuente: Elaboración propia}

Según autores como Míguez (2015) el requisito que necesitan cumplir las mujeres Disney para pertenecer a la estructura política de la monarquía es por linaje directo de su familia o indirecto tras contraer matrimonio con un príncipe. Estas son: Blancanieves de Blancanieves y los siete enanitos (Disney, 1937), Cenicienta de Cenicienta (Disney, 1950), Autora de La bella durmiente (Disney, 1959), Ariel de La sirenita (Ashman y Musker, 1989), Bella de La Bella y la Bestia (Hahn, 1991), Jasmine de Aladdin (Clements y Musker, 1992), Tiana de Tiana y el sapo (del Vecho y Lasseter, 2009), Rapunzel de Enredados (Conli, 2010) y Elsa y Anna de
Frozen: El reino de hielo (Del Vecho y Lasseter, 2013).

Partiendo de este postulado teórico, otras mujeres protagonistas del conjunto de filmes analizados se excluyen de esta categorización como es el caso de Pocahontas en Pocahontas (Pentecost, 1995) - hija del jefe de una tribu india norteamericana en la actual región de Virginia - , Mulan en Mulan (Coats, 1998) mujer oriental que contrae matrimonio con el hijo del general del ejército imperial en la China dinástica - y Vaiana en Vaiana (Shurer, 2016) - hija del jefe de una tribu de la actual Indonesia -.

\section{Variables de estudio}

En cuanto a las variables de estudio seleccionadas para la revisión crítica de largometrajes de Walt Disney se establecen dos grandes grupos. Por un lado, las características físicas (belleza occidental, también feminidad y sensualidad en las figuras); por otro lado, los rasgos de la personalidad e identidad (amor romántico, domesticidad, damiselas en peligro, rebeldía y colectivo LGBT).

\section{Método}

Respecto al método utilizado y/o los pasos que se siguen en esta fase de la investigación se comparten los siguientes.

- Revisión bibliográfica sobre cultura visual, Walt Disney y personajes femeninos de la productora.

- Visionado y análisis crítico de los largometrajes en los que las protagonistas son princesas.

- Categorización de las características de dichas mujeres miembros de la realeza.

- Contra-discurso educativo ante los estereotipos dispensados por Walt Disney por medio del trabajo artístico de Palombo (2014) ¿Te gustamos todavía? 


\section{Instrumentos}

El instrumento utilizado para esta investigación es la tabla visual de resultados (Marín-Viadel y Roldan, 2014) en recurso propio de la Investigación Basada en las Artes (Eisner, 2004) en el que se categorizan y cuantifican los resultados recurriendo a las imágenes donde se ven reflejadas dichas características e ítems analizados.

\section{Tabla 2}

Tabla visual de resultados en relación a las características físicas, psicológicas y de identidad de las princesas Disney en la colección "clásicos".

\section{Características físicas}

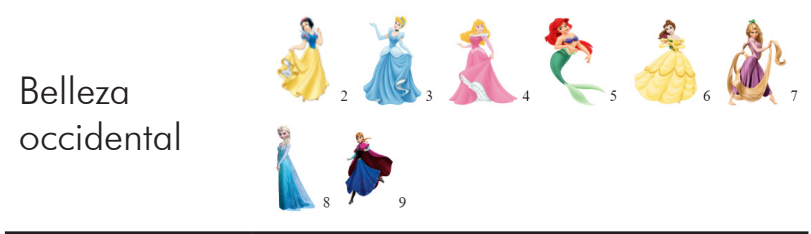

Feminidad y sensualidad en las figuras

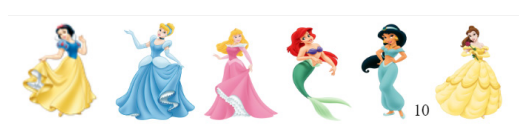

Características de la personalidad y la identidad

Amor

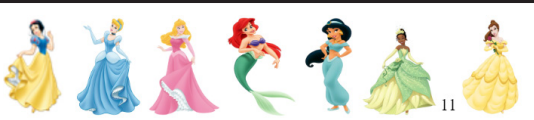

romántico

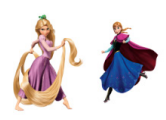

Domesticidad
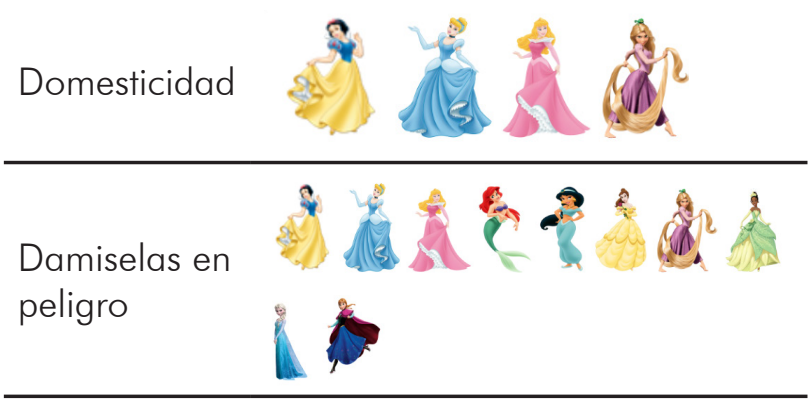

Rebeldía

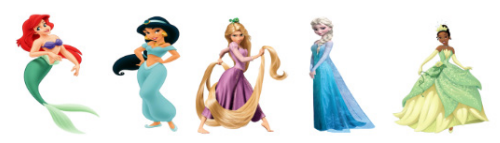

Colectivo

LGBT
En primer lugar, respecto a la belleza occidental (Míguez, 2015; Towbin, Haddock, Zimmerman, Lund y Tanner 2011) de las princesas Disney como característica física de los dibujos animados que recrea esta productora en sus largometrajes, se advierte una gran presencia (8/10) siendo una minoría (2/10) las que no se ubican dentro de este panorama geográfico. Centrando la atención en las imágenes compartidas se presencia que todas ellas pertenecen al mundo occidental-europeo, tal y como se representa con la tez pálida del rostro de cada una de ellas. Blancanieves y Rapunzel se ubican geográficamente en Alemania; Cenicienta, Aurora y Bella en Francia; y Ariel, Elsa y Anna en los países Nórdicos. De esta manera, Walt Disney transmite un mensaje racista y separatista que cala en el subconsciente de la audiencia y que subleva la alteridad con respecto a la raza blanca - considerada como superior por tradición histórica; dañando el auto-concepto de quienes son niñas en otros contextos geográficos ya que no se sienten identificadas con la idea de "princesas Disney". Las dos restantes no cumplen con el prototipo de belleza occidental, ya que Jasmine proviene de Arabia Saudí y Tiana de Nueva Orleans, es decir, del territorio norteamericano que pasa a considerar a la esclavitud importada de África como parte de la ciudadanía tras la guerra de Secesión (1861-1864). Estas razas tildadas a lo largo de la historia como inferiores necesitan ser introducidas por Disney para que la productora ofrezca una falsa apa-

- Debido a que las imágenes seleccionadas sobre las princesas Disney son las mismas para cada una de ellas, simplemente se referencian una vez con una nota al pie de página. Se citan al pie de página para no sobrecargar la tabla.

${ }^{2}$ Walt Disney (1937). Blancanieves en Blancanieves y los siete enanitos (Disney, 1937).

${ }^{3}$ Walt Disney (1950). Cenicienta en Cenicienta (Disney, 1950).

${ }^{4}$ Walt Disney (1959). Aurora en La bella durmiente (Disney, 1959).

${ }^{5}$ Walt Disney (1989). Ariel en La sirenita (Ashman y Musker, 1989).

${ }^{6}$ Walt Disney (1991). Bella en La bella y la bestia (Hahn, 1991).

7 Walt Disney (2010). Rapunzel en Enredados (Conli, 2010).

${ }^{8}$ Walt Disney (2013). Elsa en Frozen: el reino de hielo (del Vecho y Lasseter, 2013).

${ }^{9}$ Walt Disney (2013). Anna en Frozen: el reino de hielo (del Vecho y Lasseter, 2013).

${ }^{10}$ Walt Disney (1992). Jasmine en Aladdin (Clements y Musker, 1992).

11 Walt Disney (2009). Tiana en Tiana y el sapo (del Vecho y Lasseter, 2009). 
riencia de apertura, inclusión y diversidad. No obstante, este es un intento fallido y muy superficial en tanto que a pesar de variar el tono de piel de estas dos princesas, sus rasgos faciales siguen correspondiéndose con los promovidos en la belleza de la mujer occidental; no hay cabida para los ojos característicos de la población arábiga ni para las voluminosas y redondeadas narices de la comunidad africana. Algunos ejemplos extraídos literalmente de los filmes que reflejan el ideal de belleza occidental en las princesas son: "es una criatura tan linda y graciosa que es la más bella de toda la tierra" para Blancanieves, "tan solo tu belleza es más que suficiente" para Ariel o "también su nombre dice que ella es bella, es más bonita que una flor" para Bella.

En segundo lugar, la feminidad y la sensualidad en las figuras es otro de los elementos definitorios de las mujeres Disney que pertenecen a la realeza, apuntándose la presencia de este ítem en 6 de las 10 figuras analizadas, siendo únicamente 4 las que no presentan estos rasgos. Precisamente, son las tres últimas princesas de la colección a quienes no se les atribuye un género femenino que se relacione con su sexo de mujer. Rapunzel no recurre a sus atributos físicos para coquetear o enamorar al ladrón que le acompaña en sus aventuras, sino que el sentimiento aflora entre la pareja gracias a la personalidad fuerte y decidida de la princesa. Elsa tampoco pretende enamorar a ningún hombre, más bien los aleja de su vida por la condición de hechicera del hielo que acontece a su ser, además de presentar movimientos fuertes y poco femeninos como los generados en las acciones que hielan su ciudad. Anna es la única que muestra una obsesión respecto a la experimentación de un amor romántico de corte heterosexual, pero su manera de proceder cuando conoce al príncipe Hans - quien resulta ser el villano principal del filme - carece de feminidad; Ana es una princesa patosa que se cae sobre una barca y repetidas veces al suelo. En contraposición, el resto de princesas Disney; independientemente de estar motivadas intrínsecamente por el desarrollo del sentimiento de amor romántico con un hombre blanco, heterosexual y rico; siempre recurre a acciones estereotipadas que los embelesan. Algunos ejemplos de ello son el pestañeo de Blancanieves para encandilar a los siete enanitos y que se le permita vivir con ellos en la cabaña, Cenicienta y Aurora son capaces de atraer a sus respectivos príncipes simplemente bailando con ellos y sin mantener una conversación, también Ariel, Jasmine y Bella recurren a movimientos sensuales de sus caderas al andar delante de los varones. Esta idea de feminidad está respaldada por intelectuales como Garabedian (2014) y Walsh (2010), quienes justifican la agudización de este atributo con la llegada de la tercera ola feminista, momento en que la vestimenta de la mujer cambia drásticamente y ya se le permite enseñar gran parte de su cuerpo en público, además es esta misma quien controla su aparato reproductor gracias a los anticonceptivos femeninos.

Traspasando el plano físico y posicionando la investigación en un terreno más psicológico con la identidad y la personalidad de las figuras femeninas de la realeza Disney, se advierte que una gran mayoría de estas (9/10) experimenta un amor romántico (Supúlveda, 2013; Marín y Solís, 2017), siendo únicamente Elsa $(1 / 10)$ quien comparte muestras de afecto de tipo fraternal hacia su propia hermana Anna. De todas ellas, solo hay 4 que puramente buscan un amor de este tipo: Blancanieves, Cenicienta, Aurora y Anna. Las tres primeras piensan que lo necesitan para salvar sus propias vidas, ya que Disney les niega sentimientos de superación personal y de empoderamiento femenino. En el caso de Anna, ella busca un príncipe para que complete los vacíos emocionales que generan el fallecimiento de sus progenitores y el aislamiento de su hermana mayor. Así se daña la identidad de las niñas que consumen el producto audiovisual, transmitiéndoles un mensaje subversivo que las anima a buscar un amor romántico en sus vidas justificado por la falsa incapacidad que este sexo muestra según Disney para superarse y sobrevivir a la adversidad. El resto de princesas, aunque no apuesten por este objetivo de vida, terminan fallando a sus propios intereses y motivaciones personales tras conocer a un hombre que cambia el transcurso de su vida. Los ejemplos más significativos se advierten con Tiana, quien renuncia al emprendimiento y a su sueño de ser la gerente de su propio restaurante por salvar la vida del príncipe $\mathrm{Na}$ veen; también con Rapunzel, quien está dispuesta a acatar las órdenes de su secuestradora y vivir encerrada de por vida si así evita que Flynn sea asesinado o encarcelado.

En cuanto a la domesticidad, se entiende por princesas domésticas aquellas que pese a su condición y pertenencia a la realeza se ven 
obligadas a desarrollar las tareas del hogar. Estas representan una minoría (4/10) en contraposición a una mayoría (6/10) que gozan de su rol real y no quedan supeditadas a la domesticidad de la casa, ya que disponen de un servicio doméstico que se encarga de dichas labores. Blancanieves se convierte en la sirvienta de los siete enanitos para ganarse sus favores, Cenicienta pasa a ser la criada de su propia casa y de su familia tras que su padre fallezca y su madrastra agote la fortuna heredada, Aurora se encarga de las labores domésticas cuando vive en la cabaña del bosque con las tres hadas desarrollando el rol de tías de edad avanzada que merecen respeto y finalmente Rapunzel debe encargarse de cuidar el lugar donde vive y del que no puede salir, la torre del bosque. Estas mujeres se corresponden con las diseñadas a raíz de la segunda ola feminista (Moran, 1989; Gene, 2008), a excepción de Rapunzel. Esta situación de cambio contribuye positivamente para la construcción de la identidad del colectivo infantil a través de recursos de la cultura visual, ya que desdibuja un rol doméstico en la mujer hacia otro más emprendedor, intelectual e independiente - hay más mujeres/princesas Disney que cumplen estas características.

Llama la atención que el ítem correspondiente con damiselas en peligro se manifiesta en una totalidad de las figuras analizadas (10/10). Todas ellas tienen problemas en sus vidas que deben solucionar para cumplir sus metas - simplemente para salvar su vida. La reina Grimhilde se propone asesinar a Blancanieves al igual que Maléfica quiere hacer con Aurora; Cenicienta, Ariel, Bella, Jasmine, Anna y Elsa son secuestradas negándoles la posibilidad de ejercer su voluntad en la vida pública - introduciendo también así una idea machista en el colectivo infantil que relega a la mujer al ámbito privado mientras que es el hombre es quien se presenta en sociedad -. Esta es una visión estereotipada del género (Cantillo, 2011) que transmite un mensaje oculto que cala en el subconsciente de la sociedad, es decir, la mujer necesita ser salvada porque su condición y su sexo le destinan a sentirse acosada, violada, agredida, etc.; mientras que los hombres son aquellos seres valerosos y fuertes, con aptitudes para enfrentar problemas y ayudar al sexo opuesto y tildado de débil. Es necesario romper esta mentalidad machista que arraiga en occidente y que agrede contra la integridad física, psicológica y emocional de la mujer.
No obstante, se destaca como positivo para la formación integral de quienes consumen los largometrajes la existencia de un grupo de princesas rebeldes e inconformistas con las situaciones machistas y sexistas que se desarrollan en sus vidas, aunque la cantidad de estas se corresponde únicamente con la mitad de las figuras analizadas (5/10). Este hecho se relaciona directamente con la tercera ola feminista (Garabedian, 2014; Walsh, 2010) momento histórico en el que Disney comienza a adaptar sus personajes a la realidad social y a la identidad que define colectivamente al grupo de mujeres. Estas son princesas adolescentes y quebrantadoras de normas impuestas. Por ello, Ariel desobedece a su padre y visita repetidas veces la superficie terrestre, al igual que Jasmine se introduce en la realidad social de la ciudad de Ágraba, que se aleja drásticamente que los lujos que posee en el palacio. Esta rebeldía también se anota con Rapunzel, mujer que planea repetidas veces la huída de la torre donde su secuestradora la retiene. Por otra parte, la rebeldía de Elsa se comparte con la audiencia cuando ella renuncia a su vida en el castillo y huye al bosque, mostrando abiertamente su condición de hechicera. En el caso de Tiana, se le atribuye la condición de rebelde ya que no desiste en su deseo de emprendimiento. Este es un mensaje que contribuye y motiva a las niñas a perseguir sus metas personales y a superarse a sí mismas.

Finalmente, respecto a la relación con el colectivo LGBT, de una manera indirecta hay estudios científicos (Míguez, 2015) que contemplan la posibilidad de que el personaje de Elsa sea un guiño hacia una persona perteneciente a dicho grupo social. Al igual que les ocurre a las personas LGBT, esta princesa tiene un sentimiento de incomprensión hacia una situación innata a su ser que escapa de su entendimiento y a su aceptación, ya que no recibe una educación que apueste por la diversidad y que respete la normatividad de la diferencia. Ella de niña descubre que tiene un poder, ella es capaz de generar grandes heladas; situación ante la que su pareja de progenitores decide encerrarla y prohibirle que hable de dicha característica. Además, este personaje se construye en un momento histórico en que la cuarta ola feminista (Chamberlain, 2017) comienza su andadura; en este periodo se trabaja para ofrecer visibilidad a la mujer queer. Literalmente, en el filme aparecen ejemplos que se relacionan con el comportamiento homofóbico hacia el colectivo: "su poder seguirá crecien- 
do y creciendo, hay gran belleza en él, pero también hay peligro, debes aprender a dominarlo, el miedo será tu enemigo", "la protegeremos, aprenderá a controlarlo, seguro; hasta entonces cerraremos las puertas, reduciremos el personal, limitaremos su contacto con otras personas y ocultaremos sus poderes a todo el mundo, incluida Anna" y "no has de sentir, no han de saber". También hay comentarios emitidos por la propia Elsa que verifican su supuesta condición sexual: "soy la reina en un reino de aislamiento y soledad", "lo quise contener pero se escapó", "suéltalo, suéltalo; no lo puedo ya retener", "ya se descubrió", "déjalo escapar", "el temor que me aferraba no me va a hacer volver", "soy libre y ahora intentaré sobrepasar los límites, ya no hay reglas para mí por fin", "y un pensamiento en mí surgió y cristalizó, ya no regresaré, el pasado ya pasó", "suéltalo, suéltalo, la farsa se acabó" y "que la luz se haga otra vez". Sin embargo, no es significativa la introducción en la colección de un personaje LGBT tan superficial y con una interpretación de su sexualidad tan inespecífica. Para contribuir a una educación integral del grupo de menores se deben utilizar situaciones y personajes como la Elsa lesbiana para introducir la diversidad sexual en las aulas y contribuir a normalizarla.

\section{CONCLUSIONES Y PROPUESTA/S}

Esta investigación científica centrada en educación aspira a visibilizar los mensajes que Disney transmite a través de sus princesas, también a indicar las consecuencias que generan dichas situaciones en el desarrollo personal de las niñas que consumen sus productos y que toman a estos miembros de la realeza como modelos de referencia. Se concluye que, los ideales que transmiten las princesas Disney a través de su apariencia y discurso son:

- Disney apuesta por una belleza occidental para sus princesas, generando sentimientos de odio y desprecio hacia una alteridad perteneciente a otras culturas y localizaciones geográficas, contribuyendo a conductas racistas y problemas de autoestima en todas aquellas niñas que no cumplen con el canon e ideal impuesto por la productora.

- Se relaciona la figura de la mujer con la sensualidad y la feminidad como medio para despertar un deseo sexual y de atracción en los hombres. Transmitiéndo- se subversivamente un mensaje que subleva la figura de la mujer a la del hombre y que niega la rotura de estereotipos de género.

- En relación con esta visión de inferioridad de la mujer respecto del hombre, aparece retratado un ideal de amor romántico riqueza, occidente, estereotipos, belleza y heterosexualidad - que las acompaña a lo largo de sus historias de vida.

- El amor romántico se explica en términos de salvación de la existencia de las princesas. Disney las retrata como el sexo débil justificándose así para ubicar su destino junto a un varón que las libere de la peligrosidad que acontece en sus vidas. Contribuyendo una vez más al sexismo de esta productora.

- Como aspecto positivo se muestra la escasez de princesas que destinan sus vidas al ámbito doméstico, animando con las restantes al grupo de niñas a empoderarse y animarse a ejercer sus derechos como personas y miembros activos de la vida pública y política de la sociedad donde se encuentran. Apreciándose el aumento que tienen las princesas rebeldes e intransigentes a medida que los momentos históricos se desarrollan y las olas feministas impulsan cambios.

- Con todo, la existencia de un único personaje femenino con indicios de pertenecer al colectivo LGBT y su presentación en el largometraje como figura no normativa, son los motivos principales por los que se tilda a Walt Disney de productora homofóbica, que contribuye a despertar sentimientos de odio hacia las personas sexualmente diversas.

Tras estas conclusiones generadas a raíz del análisis cualitativo de las princesas Disney se plantean varios interrogantes que despiertan el interés y la preocupación de la persona a cargo de esta investigación educativa: ¿̇qué cabida tiene la diversidad funcional en las producciones de animación de Walt Disney?, ¿qué representación se destina para las mujeres funcionalmente diversas en la colección estudiada?, ¿qué alternativas tiene una persona con diversidad funcional para sentirse reconocida 
y socialmente visible con los largometrajes de Walt Disney?

Se destaca que a lo largo de los 79 años en los que se extiende históricamente la colección "clásicos Disney" la representación que se comparte de la mujer cambia drásticamente y se dirige hacia unos focos más tolerantes, abiertos, equitativos e igualitarios con respecto a los derechos universales de las personas. No obstante, no incluye a colectivos con diversidad funcional, ni si quiera los presenta de manera secundaria y esta situación daña el auto-concepto de quienes consumen el producto y no cumplen con los cánones de belleza occidental construidos y arraigados. La única explicación relacionada con dicha situación se centra en la ideología y firma Disney que únicamente apuesta por un mundo idealizado, maquillado y que de forma exclusiva tolera una normatividad tradicional.

Por ello, ya que esta productora de animación no contempla la diversidad funcional, cada vez más presente en quienes componen el colectivo infantil, se necesita recurrir a contra-discursos elaborados por artistas contemporáneos para visibilizarlas y convertir en normativo aquello que se niega durante siglos. No se habla de una integración entendida en términos de introducción de personas funcionalmente diversas en grupos normativos, sino de una inclusión real que entienda sus diferencias y que adapte los espacios, tiempos, tareas educativas, etc., para que alcance los mismo objetivos. Por tanto, la idea que se resalta en este discurso es la defensa de la igualdad en derechos humanos y posibilidades sociales partiendo de una diversidad y diferencia de origen que resulta innegable.

\section{REFERENCIAS BIBLIOGRÁFICAS}

Ali, A. H. (2006). Yo Acuso. Defensa de la emancipación de las mujeres musulmanas. Barcelona: Círculo de lectores/Galaxia Gutemberg.

Alonso-Sanz, A. (2013). A favor de la Investigación Plural en Educación Artística. Integrando diferentes enfoques metodológicos, 25(1), $111-119$.
Un recurso artístico al que se invita a recurrir en las aulas es al trabajo de Palombo (2014) ¿Te gustamos todavía? Esta es una imagen en la que aparecen retratadas diferentes princesas y mujeres Disney con diversidad funcional. Son miembros de la realeza con inmovilidad en sus extremidades inferiores - Mulan, Pocahontas, Ariel, Blancanieves y Bella -, con mutilaciones en las superiores - Mulan, Cenicienta, Aurora, Tiana y Jasmine - e incluso personas invidentes - Tiana y Jasmine - tal y como se aprecia por la blancura de sus pupilas. La introducción de alternativas como esta contribuye a la normatividad de la diversidad funcional entre los grupos de estudiantes, que debe ser el paso previo a la inclusión real de quienes no son normativas en la sociedad occidental existente. Todo ello, tras un análisis crítico de la situación actual. Hasta que la sociedad no sea consciente de la diversidad existente no es posible trabajar para incluirla de un modo real ni de apostar por la igualdad partiendo de la diferencia. A continuación se comparte la imagen diseñada por Alexsandro Palombo.

Figura 1

Alexsandro Palombo (2015). ¿̇Te gustamos todavía?

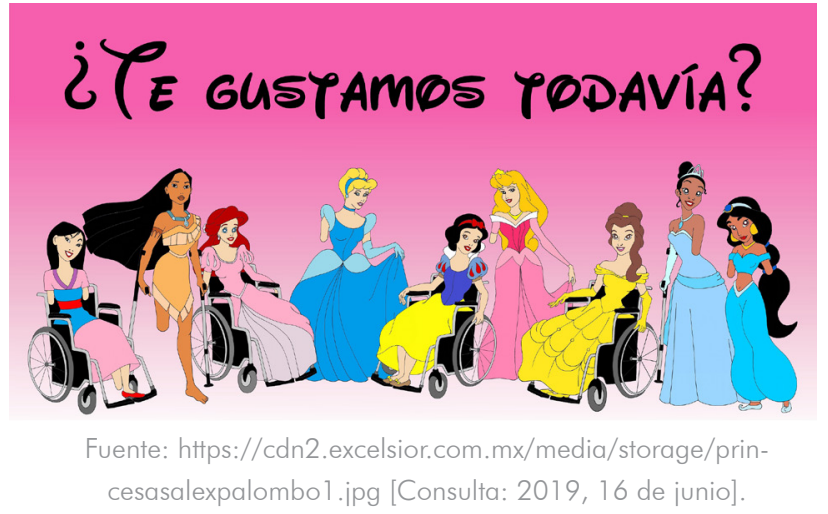

Asebey, A. M. d. R. (2011). Disney en la aculturación de la niñez latinoamericana. Revista de Psicología Trujillo, 13(2), 241-251.

Ashman, H. y Musker, J. (productores) y Clements, R. y Musker, J. (directores). (1989). La Sirenita [Cinta cinematográfica]. Estados Unidos: Walt Disney Pictures. 
Bayhan, S. y Caner, A. (2017). Schools in the Nexus of Neoliberal Urban Transformation and Education Policy Change. JCEPS The Journal for Critical Education for Policy Studies, 15(3), 145-173.

Boy, D. (2013). Dyrtiland: las princesas Disney se desudan. Mis gafas de pasta ya no están de moda. Recuperado de: http://www.misgafasdepasta.com/dirtyland-las-princesasdisney-se-desnudan-por-dillon-boy/ [Consulta: 2018, 28 de diciembre].

Cantillo, C. (2011). Análisis de la representación femenina en los medios. El caso de las princesas Disney. Cuadernos de cine y educación, 78, 51-61.

Carr, J. (2015). Neoliberal and Neoconservative Inmiseration Capitalism in England: Policies and Impacts on Society and on Education. JCEPS The Journal for Critical Education for Policy Studies, 13(2), 38-82.

Chamberlain, P. (2017). Affective Temporalities. En P. Cgamberlain (Ed.). The Feminism Fourth Wave (pp. 73-106). Londres: Palgrave momillan.

Clements, R. y Musker, J. (productores) y Clements, R. y Musker, J. (directores). (1992). Aladdin [Cinta cinematográfica]. Estados Unidos: Walt Disney Pictures y Walt Disney Feature Animation.

Coats, P. (productor) y Cook, B. y Bancroft, T. (directores). (1998). Mulan [Cinta cinematográfica]. Estados Unidos: Walt Disney Pictures y Walt Disney Feature Animation.

Conde, F. (1990). Un ensayo de articulación de las perspectivas cuantitativa y cualitativa en la investigación social. Reis, 51 (90), 91 117.

Conli, R. (productor) y Greno, N. y Howard, B. (directores). (2010). Enredados [Cinta cinematográfica]. Estados Unidos: Walt Disney Animation Studios.

Czarnecki, T. (2012). La muerte de las princesas Disney por Thomas Czarnecki. Recuperado de: https://www.oldskull.net/fotografia/ la-muerte-de-las-princesas-disney-por-thomas-czarnecki/ [Consulta: 2018, 28 de diciembre].

Del Vecho, P. y Lasseter, J. (productores) y Buck, C. y Lee, J. (directores). (2013). Frozen: El reino de hielo [Cinta cinematográfica]. Estados Unidos: Walt Disney Animation Studios y Walt Disney Pictures.

Del Vecho, P. y Lasseter, J. (productores) y Clements, R. y Musker, J. (directores). (2009). Tiana y el sapo [Cinta cinematográfica]. Estados Unidos: Walt Disney Pictures.

Disney, W. (productor) y Clark, L., Geronimi, C., Larson, E. y Reitherman, W. (directores). (1959). La Bella Durmiente [Cinta cinematográfica]. Estados Unidos: Walt Disney AnimationStudios.

Disney, W. (productor) y Cottrell, W., Hand, D., Morey, L., Pearce, P. y Sharpsteen, B. (directores). (1937). Blancanieves y los siete enanitos [Cinta cinematográfica]. Estados Unidos: Walt Disney Pictures.

Disney, W. (productor) y Geronimi, C., Jackson, W. y Luske, H. (directores). (1950). Cenicienta [Cinta cinematográfica]. Estados Unidos: Walt Disney Productions.

Eisner, E. W. (2004). El arte y la creación de la mente: el papel de las artes visuales en la transformación de la conciencia. Barcelona: Paidos Iberica Ediciones SA.

Eisner, E. W. y Barone, T. (2006). Arts-Based Educational Research. En J. L. Green, G. Camilli y P. B. Elmore (Eds.). Handbook of complementary methods in education research (pp. 95-109). Mahwah, Nueva Yersey: AERA.

Freire, P. (2007) [1970]. Pedagogía del Oprimido. Madrid: Siglo XXI.

Garabedian, J. (2014). Animating Gender Roles: How Disney is Redefining the Modern Princess. James Madison Undergraduate Research Journal, 2(1), 22-25. Recuperado de: http://commons.lib.jmu.edu/cgi/viewcontent.cgi? article $=1009$ ycontext = imuri [Consulta: 2017, 8 de diciembre].

Gene, S. (2008). Great Depression. The Concise Encyclopedia of Economics [Archivo en línea]. Recuperado de: http://www.econlib.org/library/Enc/GreatDepression.html [Consulta: 2017, 3 de diciembre]. 
Gergen, K. J. (1997). El Yo Saturado. Dilema de Identidad en el Mundo Contemporáneo. Barcelona: Paidós Contextos.

Giovanni, E. (2007). Disney Films: Reflections of the Other and the Self. Cultura, lenguaje y representación: revista de estudios culturales de la Universidad Jaume I, 4, 91-109.

Granado, M. (2003). Educación audiovisual en educación infantil. Comunicar, 20, 155 158.

Hahn, D. (productor) y Trousdale, G. y Wise, K. (directores). (1991). La Bella y la Bestia [Cinta cinematográfica]. Estados Unidos: Walt Disney Pictures y Walt Disney Feature Animation.

Hoax, S. (2014). Happy never after. Recuperado de: http://www.issueno206.com/ saint-hoax-happy-never-after/ [Consulta: 2018, 28 de diciembre].

Marín, R. (2005). La "Investigación Educativa Basada en las Artes Visuales" o "Arte investigación educativa". En R. Marín (Ed.). Investigación en Educación Artística (pp. 223-274). Granada: Editorial Universidad de Valencia.

Marín, V. y Solís, C. (2017). Los valores transmitidos por las mujeres de las películas Disney. Ciencias Sociales, 23, 37-55.

Marín-Viadel, R. y Roldán, J. (2014). 4 instrumentos cuantitativos y 3 instrumentos cualitativos en Investigación Educativa Basada en las Artes Visaules. Universidad de Granada.

Míguez, M. (2015). De Blancanieves, Cenicienta y Aurora a Tiana, Rapunzel y Elsa: ¿̇qué imagen de la mujer transmite Disney? Revista Internacional de Comunicación y Desarrollo, 2, $41-58$.

Monleón, V. (2018a). "El malo no gana": experiencia educativa sobre vilanos y villanas de la cultura visual infantil. Prácticas Artísticas no Ensino Básico e Secundário, 6(3), $18-26$

Monleón, V. (2018b). "El malo de la película". Estudio de las principales figuras malvadas en la colección cinematográficas clásicos Disney. EARI, Educación Artística Revista de Investigación, 9, 131-148.
Moran, M. (1989). 1930's, America-Feminist Void? The Status of the Equal Rights Movement during the Great Drepression [Archivo en línea]. Recuperado de: http://www.loyno.edu/ history/journal/1988-9/moran. htm [Consulta: 2017, 3 de diciembre].

Nilsson, H. (2013). Paintings by Herr Nilsson. GuyHepner. Recuperado de: https://guyhepner.com/artist/herr-nilsson-street-art-for-sale/paintings-by-herr-nilsson/ [Consulta: 2018, 28 de diciembre].

Pallarès, M. (2014). El legado de Paulo Freire en la escuela de hoy. De la alfabetización crítica en medios de comunicación. Teoría educativa, 26, 59-76.

Palombo, A. (2014). ¿̇Te gustamos todavía? Recuperado de: http://www.anundis.com/ profiles/blogs/te-gustamos-todav-a-as-sellama-la-serie-de-dibujos [Consulta: 2018, 28 de diciembre].

Pentecost, J. (productor) y Gabriel, M. y Golsdberg, M. (directores). (1995). Pocahontas [Cinta cinematográfica]. Estados Unidos: Walt Disney Pictures.

Pereira, Z. (2011). Los diseños de método mixto en la investigación en educación: Una experiencia concreta [archivo en línea]. Revista electrónica educare, 15(1), 15-29. Recuperado de: file://C:/Users/2019/ Downloads/Dialnet-LosDisenosDeMetodoMixtoEnLalnvestigacionEnEducacio-3683544\%20(1).pdf [Consulta: 2019, 13 de abril].

Porta, L. y Silva, M. (2003). La investigación cualitativa: El Análisis de Contenido en la investigación educativa. Red Nacional Argentina de Documentación e Información Educativa, 1-18.

Ramírez, F. H. y Zwerg-Villegas, A. M. (2012). Metodología de la investigación: más que una receta. AD-minister. Universidad EAFIT, 20, $91-111$.

Ramos, C. A. (2015). Los paradigmas de la investigación científica. Av. Psicol., 23(1), 9-17.

Shurer, O. (productor) y Clements, R. y Musker, J. (productor). (2016). Vaiana [Cinta cinematográfica]. Estados Unidos: Walt Disney Pictures y Walt Disney Animation Studios. 
Supúlveda, P. (2013). El mito del amor romántico y su pervivencia en la cultura de masas. Ubisunt? Revista de Historia, 28, 100109.

Towbin, M. A., Haddock, S. A., Zimmerman, T. S., Lund, L. K. y Tanner, L. R. (2003) Images of Gender, Race, Age and Sexual Orientation in Disney Feature-Length Animated Films. Journal of Feminist Family Therapy, 15(4), 12-44.

Vilela, B. (1977). Bibbidi Bobbidi Boo. Catálogo Das Artes. Recuperado de: https://www. catalogodasartes.com.br/obra/DUUADG/ [Consulta: 2018, 28 de diciemrbe].

Walsh, K. (2010). The 1960s: A decade of change for women. US News, 12 [archivo en línea]. Recuperado de: http://www. usnews.com/news/articles/2010/03/12/ the-1960s-a-decade-of-change-for-women [Consulta: 2017, 3 de diciembre]. 
